\title{
Self-Esteem Evaluation in Children and Adolescents Suffering from ADHD
}

\author{
Luigi Mazzone ${ }^{1, *}$, Valentina Postorino ${ }^{1}$, Laura Reale ${ }^{2}$, Manuela Guarnera ${ }^{2}$, Valeria Mannino ${ }^{2}$, \\ Marco Armando ${ }^{1}$, Laura Fatta ${ }^{1}$, Lavinia De Peppo ${ }^{1}$ and Stefano Vicari ${ }^{1}$ \\ ${ }^{I}$ Child Neuropsychiatry Unit, Department of Neuroscience, I.R.C.C.S. Children Hospital Bambino Gesu', Rome, Italy \\ ${ }^{2}$ Division of Child Neurology and Psychiatry, Department of Pediatrics, University of Catania, Italy
}

\begin{abstract}
Background: Several recent studies investigated the relationship between self-esteem and ADHD, however, the results are still controversial. In the present study we analyze the characteristics of self-esteem in a sample of children and adolescents suffering from ADHD, with a particular focus on the relationship between ADHD symptoms severity and treatment strategies.

Methods: A total of 85 patients with ADHD (44 drug-free and 41 drug-treated, 23 of which atomoxetine-treated and 18 Methylphenidate-treated) and 26 healthy controls were enrolled in the study in order to evaluate self-esteem using the Self-esteem Multidimensional Test (TMA).

Results: ADHD subjects revealed lower scores on all self-esteem domains compared to controls. Both ADHD drug-free (47.1\%) and ADHD drug-treated (44.1\%) groups showed significantly higher rates of subjects in the pathological range as compared to normal control group $(8.8 \%)(p<.001)$ with a higher percentage of subjects in the pathological range. Among ADHD drug-treated subjects, the methylphenidate group showed higher self-esteem scores as compared to the atomoxetine group.

Conclusion: A lower self-esteem profile is more common in subjects suffering from ADHD than in healthy controls, suggesting the importance of an early detection of psychological well-being in these children in order to reduce the ADHD symptoms long-term impacts.
\end{abstract}

Keywords: Adolescents, ADHD, Atomoxetine, Children, Methylphenidate, Self-esteem.

\section{INTRODUCTION}

Attention Deficit Hyperactivity Disorder (ADHD) is one of the most common developmental disorders with a prevalence of $3-7 \%$ in the general population [1] and is associated with significant impairment symptoms. As a consequence of pervasiveness, ADHD can negatively interfere with the general well-being, as well as with social life, academic performance, and development of social skills [2-5], which in turn, can lead to low self-esteem.

Self-esteem is a complex construct that has been described in a variety of different ways [6,7]. Generally, it can be defined as a cognitive and emotional concept of an individual about himself, and recently there has been a growing consensus that self-esteem is a multidimensional construct involving different areas such as competence, achievement, and a judgment of self-worth [6, 8-10]. Several studies investigating the relationship between self-esteem and different psychiatric disorders indicate severe inverse relationships between self-esteem and these conditions [11-13]. In line with this, the link between ADHD and low self-esteem was

*Address correspondence to this author at the Child Neuropsychiatry Unit, Department of Neuroscience, I.R.C.C.S. Children Hospital Bambino Gesu', Piazza S. Onofrio,4, 00165, Rome, Italy; Tel: 0668592734;

Fax: 0668592450; E-mail: gigimazzone@yahoo.it also demonstrated by cross-sectional studies [14-18]. An explanation for these results could be addressed to the multiple failures that these patients report in different social contests (e.g. school, family, etc.), and that drive them to experience a lower perception of their competency as compared to peers. Furthermore, recent findings from longitudinal studies also showed that children diagnosed with ADHD reported lower self-esteem in adolescence as compared to controls $[16,19,20]$. However, other studies found no differences between clinically diagnosed ADHD and controls in terms of self-esteem, showing instead that children with ADHD tend to overestimate their own competence, despite the various problems they experience, implementing a phenomenon called "positive illusory bias", a thinking style characterized by positive illusions which could also be a means of selfprotection [21-24].

Independently of the controversial results, all the studies finally agreed that a positive self-esteem may help children with ADHD to cope with failures or difficulties in everyday life $[16,23]$, thus emphasizing the importance of self-esteem for performance and outcomes in ADHD patients [16].

However, so far, only few studies have investigated how this construct can be influenced by therapeutical treatments. Indeed, only two studies directly investigated the effect of methylphenidate on self-esteem in ADHD patients, reporting 
Table 1. Clinical Characteristics of the Sample

\begin{tabular}{|c|c|c|c|c|}
\hline \multicolumn{4}{|c|}{ ADHD Groups $\left(\mathbf{N}^{a}=\mathbf{8 5}\right)$} & Controls $(\mathrm{N}=26)$ \\
\hline \multicolumn{5}{|l|}{ Type of ADHD } \\
\hline Inattentive $\mathrm{N}(\%)$ & $7(8.2 \%)$ & - & $2(2.4 \%)$ & - \\
\hline Combined N(\%) & $36(42.4 \%)$ & $23(27 \%)$ & $14(16.5 \%)$ & - \\
\hline \multicolumn{5}{|l|}{ Comorbid disorders } \\
\hline $\mathrm{SLD}^{b} \mathrm{~N}(\%)$ & $17(20 \%)$ & $1(1.2 \%)$ & $9(10.6 \%)$ & - \\
\hline Anxiety Disorder N (\%) & $18(21.2 \%)$ & $4(4.7 \%)$ & $4(4.7 \%)$ & - \\
\hline Other & $3(3.5 \%)$ & $3(3.6 \%)$ & - & - \\
\hline \multicolumn{5}{|l|}{ SNAP-IV Subscales } \\
\hline Inattentive $\mathrm{M}^{d}\left(\mathrm{SD}^{e}\right)$ & $18.13(4.7)$ & $19.63(4.3)$ & $17.00(5.1)$ & $5.04(1.1)$ \\
\hline Hyperactive/Impulsive M (SD) & $15.67(6.4)$ & $19.58(4.8)$ & $14.85(6.3)$ & $3.04(1.1)$ \\
\hline Combined $\mathrm{M}(\mathrm{SD})$ & $33.80(9.9)$ & $39.21(6.7)$ & $31.84(9.6)$ & $8.08(1.5)$ \\
\hline Oppositional Defiant M(SD) & $11.00(5.0)$ & $13.52(5.5)$ & $12.15(5.2)$ & $4.15(1.3)$ \\
\hline
\end{tabular}

${ }^{a}$ Number of subjects;

${ }^{b}$ Specific Learning Disorder;

${ }^{c}$ Oppositional Defiant Disorder;

${ }^{d}$ Mean;

${ }^{e}$ Standard Deviation.

that patients treated with stimulants had significantly higher self-esteem as compared to un-medicated subjects [25, 26]. More studies have been conducted on patients treated with atomoxetine, demonstrating an improvement of self-esteem that, in turn, lead to an impact on emotional well-being and quality of life [5, 8, 27-39]. However, to our knowledge, only one of these studies used a specific tool to evaluate selfesteem [8].

In the present study we analyze the characteristics of selfesteem in a sample of children and adolescents suffering from ADHD, with a particular focus on the relationship between ADHD symptoms severity and treatment strategies.

\section{MATERIALS AND METHODOLOGY}

\section{Participants and Procedure}

A total of 85 children and adolescents ( 80 males and 5 females; age range $8-15$ years; mean age \pm SD: $10.03 \pm 2.0$ ) suffering from ADHD, referred to the Child and Adolescent Neuropsychiatry Unit of the Paediatric Department at the University of Catania (Italy) and to the Child and Adolescent Neuropsychiatry Unit of the Children's Research Hospital Bambino Gesù of Rome (Italy) throughout the year 2010 were enrolled in this study. All ADHD patients had been diagnosed according to the DSM-IV-TR criteria [1] by a psychiatry experienced with children and adolescent.
Moreover, Kiddie-Schedule for Affective Disorders and Schizofrenia for School-Age Children/Present and Lifetime Version (K-SADS-PL) [40] was administered to all the patients' parents by an experienced trained clinician. An interrater reliability analysis using the Kappa statistic was performed to determine consistency among DSM-IV-TR criteria and K-SADS-PL diagnosis. The interrater reliability for the raters was found to be an almost perfect agreement (Kappa = 0.913, $p<.000)$. ADHD subtypes included the following: combined type $(n=73)$; inattentive type $(n=9)$; hyperactive/impulsive type $(n=3)$ (Table 1$)$. Variance analysis performed to evaluate ADHD symptoms severity in the presence of a comorbid Oppositional Defiant Disorder assessed by SNAP-IV [41, 42], showed significant differences between all ADHD groups and normal controls in all SNAP-IV Subscales (Inattentive: $p=.000 ;$ Hyperactive/Impulsive: $p=.000$; Combined: $p=.000$; Oppositional Defiant: $p=.000$ ) with higher mean scores of symptoms severity reported by patients treated with atomoxetine as compared to drug-free patients and patients treated with methylphenidate (Table 1). Moreover, the SNAP-IV Hyperactive/Impulsive Subscale revealed a significant difference within the ADHD group $(p=.042)$, with higher mean scores of symptoms severity reported by patients treated with atomoxetine $(19.58 \pm 4.8)$ as compared to drug-free patients $(15.67 \pm 6.3)$ and patients treated with methylphenidate $(14.85 \pm 6.2)$ (Table 1). 
All the subjects included in the study had an intelligence quotient $\geq 80$ evaluated by Leiter-R $[43,44]$. Of these 85 ADHD patients, 44 subjects ( 40 males and 4 females; age range 8-15 years; mean age \pm SD: $9.97 \pm 2.8$ ) were drug-free and 41 subjects ( 40 males and 1 female; age range 8-15 years; mean age \pm SD: $10.70 \pm 2.0$ ) received a pharmacological treatment. Among them, 23 male patients (age range 8-15 years; mean age $\pm \mathrm{SD}: 10.03 \pm 2.0$ ) were treated with atomoxetine at dose of $10-110 \mathrm{mg} /$ day (mean:1.28 $\mathrm{mg} / \mathrm{kg} /$ day) and 18 patients (17 males and 1 female; age range 8-15 years; mean age \pm SD: $9.85 \pm 2.2$ ) received methylphenidate (20-30 mg/day). All the patients included in the clinical samples had not been previously diagnosed nor treated with atomoxetine, or with stimulants and other psychotropic medications.

All the participants who received a medical treatment were assessed for self-esteem evaluation after 6 months from the beginning of the pharmacological therapy.

Twenty-six normal control male subjects (age range 8-14 years; mean age \pm SD: $11.29 \pm 1.4$ ) randomly selected from a database of healthy children attending a well-being paediatric clinic for routine checks were also included in the study. All the parents and children included in the healthy control group completed the K-SADS-PL with an experienced trained clinician. None of the control subjects fulfilled the criteria for any psychiatric disorder. Moreover none of them had ever used any psychotropic medication, nor were they undergoing any psychological therapy at the time of the study.

The clinical characteristics of the subjects participating in the study are summarized in Table $\mathbf{1}$.

All the parents of the participants who accepted to take part in the research signed a consent form, and children and adolescents assented to participation.

\section{Assessment of Clinical Symptoms}

To assess the presence of an ADHD and/or a comorbid disorder, the Kiddie-Schedule for Affective Disorders and Schizofrenia for School-Age Children/Present and Lifetime Version (K-SADS-PL) [40] was administered to the patients' parents by an experienced trained clinician.

The K-SADS-PL is a semi-structured psychiatric interview that ascertains both lifetime and current diagnostic status based on DSM-IV-TR criteria. The K-SADS-PL includes three components: introductory interview, screen interview, and five diagnostic supplements for the evaluation of psychiatric disorders. The skip-out criteria in the screen interview specify which sections of the supplements, if any, should be completed.

To evaluate the presence of a comorbidity with Oppositional Defiant Disorder, as well as the subtype and the symptoms severity of ADHD, all the parents of the clinical and control samples completed the Swanson, Nolan, and Pelham Rating Scale-IV (SNAP-IV) [41, 42].

The SNAP-IV is a 26-item questionnaire in a 4-point Likert scale that is used to evaluate ADHD symptoms and severity, and it is completed by parents and teachers. The 26 items include 18 items for ADHD symptoms ( 9 for inatten- tive, 9 for hyperactive/impulsive) and 8 items for oppositional defiant disorder (ODD) symptoms as defined in the DSM-IV-TR [1]. Each item is scored on a $0-3$ scale $(0=$ not at all, $1=$ just a little, $2=$ quite a bit and $3=$ very much). The SNAP-IV consists of Inattentive, and Hyperactive/Impulsive, Combined Inattentive and Hyperactive/Impulsive and Oppositional Defiant subscales.

\section{Assessment of Self-Esteem}

To assess the self-esteem all the clinical and control children and adolescents completed the Self-Esteem Multidimensional Test (TMA) [45].

The TMA is based on a hierarchical model of selfesteem: it comprises six self-esteem dimensions (Personal, Skills, Emotional, School, Family, Body, Total) that partly overlap each other and partly with the core global selfesteem. The test consists of six groups of 25 items for each dimension explored and each item requires one of 4 possible answers: absolutely true, true, not true, absolutely not true. The test provides scores in six rating scales corresponding to the six self-esteem dimensions (Personal, Skills, Emotional, School, Family, Body, Total) and a global self-esteem related score. The average scores for self-esteem in the normative sample are between 85 and 115 .

\section{Data Analysis}

An interrater reliability analysis using the Kappa statistic was performed to determine consistency among DSM-IV-TR criteria and K-SADS-PL diagnosis. Standard descriptive statistics, chi-square, Student t-test, one-way ANOVA with Bonferroni comparisons, Pearson's r correlations, and linear regression models were applied to the data in order to evaluate the association between the clinical and self-esteem variables in the ADHD groups and in the normal control group. Standard descriptive statistics and Fisher's exact tests were performed to assess the association among different comorbid disorders and self-esteem domains. Moreover, comparison among ADHD groups and normal controls were performed by variance analysis to evaluate the association among ADHD symptom severity and the presence of a comorbid Oppositional Defiant Disorder. An alpha level of 0.05 was set for statistical significance. All the analyses were performed using the Statistical Package for Social Sciences (SPSS 14.0 for Windows).

\section{RESULTS}

\section{Self-Esteem Profile in the Study Population}

To evaluate self-esteem, TMA was administered to the subjects included in the study and differences between the four groups (controls, ADHD drug-free, ADHD atomoxetine-treated and ADHD methylphenidate-treated) in terms of mean scores and self-esteem profile were evaluated (Table $\mathbf{2}$ and Fig. 1). The comparison between total ADHD patients and controls, by Student t-test, showed significantly lower self-esteem scores on all TMA Subscales (Personal, Skills, Emotional, School, Family, Body and Total) in the ADHD group (Table 2). Among the ADHD sample, variance analysis indicated a significant difference in TMA Total Subscale $(p=.049)$ : particularly, ADHD patients treated with methyl- 


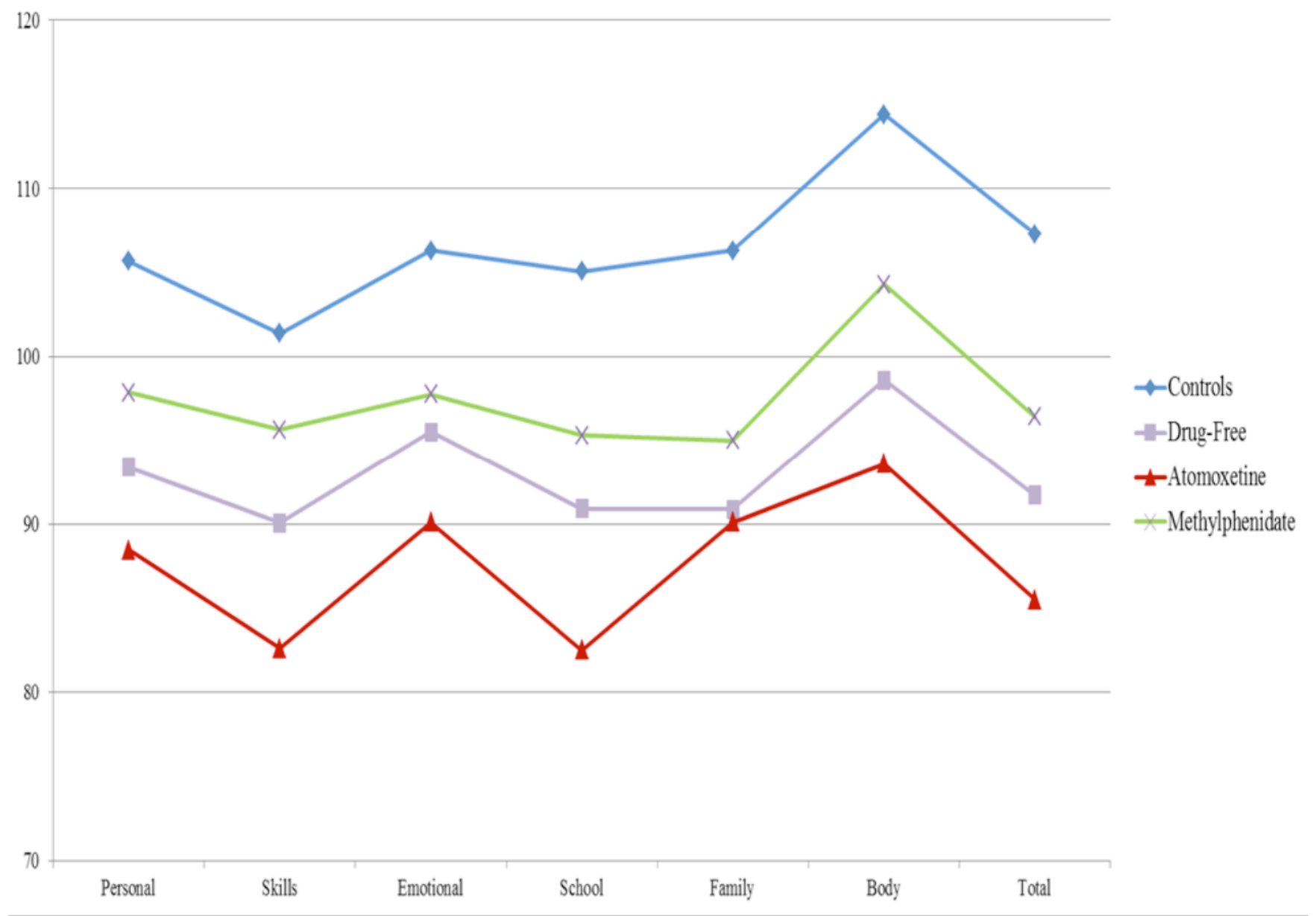

Fig. (1). Trajectories of Self-Esteem Subscales in ADHD and Control Groups.

phenidate revealed higher self-esteem mean scores in the TMA Total Subscale $(96.39 \pm 12.3)$ as compared to ADHD treated with atomoxetine $(85.48 \pm 9.9)$ as shown by Bonferroni post-hoc test $(p=.048)$. Moreover, ADHD patients treated with Methylphenidate scored significantly higher than ADHD patients treated with atomoxetine in all TMA subscales, with the only exception of TMA Family Subscale, where the difference, albeit in the same direction, failed to reach statistical significance, by Student t-test (Table 2).

\section{Self-Esteem Differences According to Age and ADHD} Symptoms Severity

Pearson's correlation was used to determine the relationship between age and self-esteem variables. Age was not found to correlate significantly with TMA scores in both ADHD and control groups. Similarly, no significant correlations were detected within the group of patients suffering from ADHD between TMA Total and Subscale scores and severity of ADHD symptoms, assessed by SNAP-IV.

\section{Subjects with a Self-Esteem Below Average Range}

Most of the ADHD patients had TMA Total scores within the pathological range $(\leq 85)$, according to the established norms. Both ADHD drug-free (47.1\%) and ADHD drug-treated $(44.1 \%)$, of which $38.2 \%$ treated with atomoxetine and $5.9 \%$ treated with methylphenidate, groups showed significantly higher rates of subjects in the pathological range as compared to normal control group $(8.8 \%)(p<$ $.001)$, whereas no significant difference was detected between ADHD drug-free and drug-treated groups. However, within the ADHD drug-treated group, patients treated with Atomoxetine showed a significantly higher rate of pathological scores for the TMA Total score as compared to patients treated with methylphenidate $(38.2 \%$ vs $5.9 \%$ respectively, $p<.003$ ).

\section{Comorbid Disorders and Self-Esteem in the Study Population}

Within the ADHD group, which comprises 85 ADHD subjects, 70 patients $(80.1 \%)$ showed at least one comorbid psychiatric disorder and $21(24.8 \%)$ had two comorbidities. In more detail, 27 children $(31.8 \%)$ had a Specific Learning Disorder, 26 children (30.6\%) had an Anxiety Disorder, 25 children $(29.4 \%)$ had an Oppositional Defiant Disorder, 5 children $(6 \%)$ had a Depressive Disorder and 6 children $(7.2 \%)$ had some other comorbid diagnosis (e.g., Tourette syndrome, Tic Disorders, Bipolar Disorder, ObsessiveCompulsive Disorder, Eating Disorder) (Table 1).

The analysis of the different comorbid diagnoses among all the domains of self-esteem, measured by TMA Test, revealed none significant differences. 
Table 2. TMA Subscales in the Study Population

\begin{tabular}{|c|c|c|c|c|c|c|c|}
\hline & \multicolumn{7}{|c|}{ TMA Subscales } \\
\hline & Personal & Skills & Emotional & School & Family & Body & Total \\
\hline \hline Groups & $\mathrm{M}^{\mathrm{a}}\left(\mathrm{SD}^{\mathrm{b}}\right)$ & $\mathrm{M}(\mathrm{SD})$ & $\mathrm{M}(\mathrm{SD})$ & $\mathrm{M}(\mathrm{SD})$ & $\mathrm{M}(\mathrm{SD})$ & $\mathrm{M}(\mathrm{SD})$ & $\mathrm{M}(\mathrm{SD})$ \\
\hline ADHD & $92.96(14.9)$ & $89.16(17.3)$ & $94.44(12.8)$ & $89.47(16.1)$ & $91.57(10.5)$ & $98.43(14.3)$ & $90.96(14.4)$ \\
\hline Controls & $105.65(15.2)$ & $101.34(14.9)$ & $106.31(10.9)$ & $105.04(15.2)$ & $106.31(11.6)$ & $114.42(21.2)$ & $107.31(12.2)$ \\
\hline & $\mathrm{t}=3.74$ & $\mathrm{t}=3.21$ & $\mathrm{t}=4.23$ & $\mathrm{t}=4.33$ & $\mathrm{t}=6.04$ & $\mathrm{t}=4.36$ & $\mathrm{t}=5.19$ \\
& $\boldsymbol{p}^{*}=\mathbf{. 0 0 0}$ & $\boldsymbol{p}^{*}=\mathbf{. 0 0 2}$ & $\boldsymbol{p}^{*}=\mathbf{. 0 0 0}$ & $\boldsymbol{p}^{*}=\mathbf{. 0 0 0}$ & $\boldsymbol{p}^{*}=\mathbf{. 0 0 0}$ & $\boldsymbol{p}^{*}=\mathbf{. 0 0 0}$ & $\boldsymbol{p}^{*}=\mathbf{. 0 0 0}$ \\
\hline Atomoxetine & $88.43(12.0)$ & $82.61(11.0)$ & $90.08(10.1)$ & $82.52(7.8)$ & $90.09(8.5)$ & $93.56(11.1)$ & $85.48(9.9)$ \\
\hline Methylphenidate & $97.83(12.2)$ & $95.61(15.5)$ & $97.72(10.3)$ & $95.28(17.3)$ & $95.00(12.6)$ & $104.28(12.9)$ & $96.39(12.3)$ \\
\hline & $\mathrm{t}=2.46$ & $\mathrm{t}=3.14$ & $\mathrm{t}=2.38$ & $\mathrm{t}=3.15$ & $\mathrm{t}=1.49$ & $\mathrm{t}=2.85$ & $\mathrm{t}=3.14$ \\
& $\boldsymbol{p}^{*}=\mathbf{. 0 1 8}$ & $\boldsymbol{p}^{*}=\mathbf{. 0 0 3}$ & $\boldsymbol{p}^{*}=\mathbf{. 0 2 2}$ & $\boldsymbol{p}^{*}=\mathbf{. 0 0 3}$ & $\boldsymbol{p}^{*}=.144$ & $\boldsymbol{p}^{*}=\mathbf{. 0 0 7}$ & $\boldsymbol{p}^{*}=\mathbf{. 0 0 3}$ \\
\hline
\end{tabular}

*Student t-test;

${ }^{a}$ Mean;

${ }^{b}$ Standard Deviation.

\section{DISCUSSION}

A positive self-esteem is crucial for a healthy psychological development and indeed a positive relationship was found between self-esteem and mental health [46]. Previous studies showed that children and adolescents suffering from ADHD have low levels of social skills and self-esteem as compared to the general population $[47,48]$ and these findings are consistent with other studies indicating that also adults with ADHD continue to have problems in many areas of functioning $[49,50]$, thus inferring the hypothesis that social functioning and self-esteem may play a role on future outcomes in ADHD [20]. In line with this, our findings show that patients with ADHD have significantly lower scores on all the administered self-esteem rating scales (personal, skills, emotional, school, family, body) compared to healthy controls, and these results are particularly relevant in light of the crucial importance of social functioning and self-esteem for healthy functioning, that is generally impaired in ADHD individuals, during development. The ability to successfully interact with peers, one of the most important aspects of social development for all ages [51], can also be impaired in ADHD children and this deficit in peer relationships can compromise interpersonal success and happiness [52] thus leading to a low self-esteem.

Overall, ADHD subjects showed significantly higher rates of self-esteem in the pathological range as compared to healthy controls, however analysis of self-esteem with respect to treatment strategies revealed no significant differences between drug-free or drug-treated ADHD groups. However, ADHD patients treated with methylphenidate showed significantly higher self-esteem scores as compared to ADHD group treated with atomoxetine, in line with previous studies showing that stimulants were associated with significantly higher self-esteem [25, 26]. However, in another study by Frankel et al. [25], this relationship was not so univocal, in that only ADHD children with a comorbid diagnosis of Oppositional Defiant Disorder reported a higher self-esteem compared to pure ADHD upon treatment with stimulants. However, in our study no significant difference was detected among different comorbid disorders in terms of self-esteem. Furthermore, we also have to point out that drug treatment had a positive influence on how the teachers interacted with children affected by ADHD, and this could contribute to indirectly improve self esteem in these children [53].

Besides these significant results, the present study shows important limitations and it should be viewed in the context of the following considerations. First, in our opinion, although cross-sectional studies are extremely useful for generating hypotheses, these hypotheses need to be further confirmed by longitudinal investigations: because of the crosssectional nature of our sample, we cannot determine the temporal relationship between ADHD and different domains of self-esteem.

Second, considering that the subjects included in the study were entirely derived from only two university clinics, this sample cannot be assumed as indicative of non-academic setting. Indeed, the sample was clinically referred and not intended to be representative of children with ADHD in the general population. Third, the control sample size was much smaller than the ADHD drug-free group limiting the generalization of our findings. Finally, self-esteem evaluation was derived from self-report questionnaires completed by the children themselves without any additional investigation of social function.

\section{CONCLUSIONS}

In conclusion the association between ADHD and selfesteem highlights the importance of early detection of children with this disorder in order to prevent the development of ADHD symptoms and to reduce long-term impacts. The development of lifespan approaches could help to clarify the role of ADHD medication either in the pathophysiological core processes or/and in the social function and self-esteem outcome. 


\section{CONFLICT OF INTEREST}

The authors confirm that this article content has no conflicts of interest.

\section{ACKNOWLEDGEMENTS}

None declared.

\section{REFERENCE}

[1] American Psychiatric Association. Diagnostic and statistical manual of mental disorders. $4^{\text {th }}$ ed. Washington, DC: American Psychiatric Association 2000.

[2] Cantwell DP. Attention deficit disorder: a review of the past 10 years. J Am Acad Child Adolesc Psychiatry 1996; 35: 978-87.

[3] Escobar R, Montoya A, Polavieja P, et al. Evaluation of patients' and parents' quality of life in a randomized placebo-controlled atomoxetine study in attention-deficit/hyperactivity disorder. J Child Adolesc Psychopharmacol 2009; 19: 253-63.

[4] Klassen AF. Miller A, Fine S. Health-related quality of life in children and adolescents who have a diagnosis of attentiondeficit/hyperactivity disorder. Pediatrics 2004; 114: 541-7.

[5] Matza LS, Rentz AM, Secnik K, et al. The link between health related quality of life and clinical symptoms among children with attention-deficit hyperactivity disorder. J Dev Behav Paediatr 2004; 25: $166-74$.

[6] Guindon MH. Self-esteem across the lifespan. New York: Taylor and Francis 2010

[7] Mruk CR. Defining self-esteem: an often overlooked issue with crucial implications. In: Kernis, M.H. Self-esteem issues and answers: a sourcebook of current perspectives. New York: Taylor \& Francis, 2006; pp. 10-7.

[8] Rosenberg M. Society and the adolescent self-image. Princeton: Princeton University Press, 1965

[9] Coopersmith S. The antecedents of self-esteem. NY: WH Freeman. 1967.

[10] Harter S. Manual for the Self-Perception Profile for Adolescents. Denver: University of Denver. 1988.

[11] Biby EL. The relation between body dysmorphic disorder and depression, self-esteem, somatization and obsessive-compulsive disorder. J Clin Psychol 1998; 54: 489-99.

[12] Ellett L, Lopes B, Chadwick P. Paranoia in a nonclinical population of college students. J Nerv Ment Dis 2003; 191: 425-30.

[13] Hoffmann JP, Baldwin SA, Cerbone FG. Onset of major depressive disorder among adolescent. J Am Acad Child Adolesc Psychiatry 2003; 42: 217-24.

[14] Sawyer MG, Whaites L, Rey JM, et al. Health-related quality of life of children and adolescents with mental disorders. J Am Acad Child Adolesc Psychiatry 2002; 41: 530-7.

[15] Barber S, Grubbs L, Cottrell B. Self-perception in children with attention deficit/hyperactivity disorder. J Pediatr Nurs 2005; 20: $235-45$.

[16] Edbom T, Lichtenstein P, Granlund M, et al. Long-term relationships between symptoms of attention deficit hyperactivity disorder and self-esteem in a prospective longitudinal study of twins. Acta Paediatr 2006; 95: 650-7.

[17] Ek U, Westerlund J, Holmberg K, Fernell E. Self-esteem in children with attention and/or learning deficits: the importance of gender. Acta Paediatr 2008; 97: 1125-30.

[18] Treuting JJ, Hinshaw SP. Depression and self-esteem in boys with attention- deficit/hyperactivity disorder: associations with comorbid aggression and explanatory attributional mechanisms. J Abnorm Child Psychol 2001; 29: 23-39.

[19] Hechtman L, Weiss G, Perlman T. Hyperactives as young adults: self-esteem and social skills. Can J Psychiatry 1980; 25: 478-83.

[20] Slomkowski C, Klein RG, Mannuzza S. Is self-esteem an important outcome in hyperactive children? J Abnorm Child Psychol 1995; 23: 303-15.

[21] Hoza B, Pelham WE, Milich R, et al. The self-perceptions and attributions of attention deficit hyperactivity disordered and nonreferred boys. J Abnorm Child Psychol 1993; 21: 271-86.

[22] Gresham FM, MacMillan DL, Bocian, et al. Comorbidity of hyperactivity-impulsivity-inattention and conduct problems: risk factors in social, affective, and academic domains. J Abnorm Child Psychol 1998; 26: 393-406.

[23] Hoza B, Pelham WE, Dobbs J, et al. Do boys with attentiondeficit/hyperactivity disorder have positive illusory self-concepts? J Abnorm Psychol 2002; 111: 268-78.

[24] Diener MB, Milich R. Effects of positive feedback on the social interactions of boys with attention deficit hyperactivity disorder: a test of the self-protective hypothesis. J Clin Child Psychol 1997; 26: 256-65.

[25] Frankel F, Cantwell DP, Myatt R, et al. Do Stimulants Improve Self-Esteem in Children with ADHD and Peer Problems? J Child Adolesc Psychopharmacol 1999; 9: 185-94.

[26] Alston CY, Romney DM. A comparison of medicated and nonmedicated attention-deficit disordered hyperactive boys. Acta Paedopsychiatr 1992; 55: 65-70.

[27] Michelson D, Faries D, Wernicke, et al. Atomoxetine ADHD Study Group Atomoxetine ADHD Study Group: Atomoxetine in the treatment of children and adolescents with attentiondeficit/hyperactivity disorder: A randomized, placebo-controlled, dose-response study. Pediatrics 2001; 108: 83-91.

[28] Buitelaar JK, Danckaert M, Gillberg, et al. Atomoxetine International Study Group A prospective, multi-center, open-label assessment of atomoxetine in non-North American children and adolescents with ADHD. Eur Child Adolesc Psychiatry 2004; 13: 249-57.

[29] Perwien AR, Faries DE, Kratochvil, et al. Improvement in healthrelated quality of life in children with ADHD: An analysis of placebo controlled studies of atomoxetine. J Dev Behav Pediatr 2004; 25: 264-71

[30] Brown RT, Perwien A, Faries, et al. Atomoxetine in the management of children with ADHD: Effects on quality of life and school functioning. Clin Pediatr 2006; 45: 819-27.

[31] Matza LS, Stoeckl MN, Shorr JM, et al. Impact of atomoxetine on health-related quality of life and functional status in patients with ADHD. Expert Rev Pharmacoecon Outcomes Res 2006; 6: 379-90.

[32] Perwien AR, Kratochvil CJ, Faries, et al. Atomoxetine treatment in children and adolescents with attention-deficit hyperactivity disorder: What are the long-term health-related quality-of-life outcomes? J Child Adolesc Psychopharmacol 2006; 16: 713-24.

[33] Prasad S, Hapin V, Poole L, et al. A multicentre, randomised, open-label study of atomoxetine compared with standard current therapy in UK children and adolescents with attentiondeficit/hyperactivity disorder (ADHD). Curr Med Res Opin 2007; 23: 379-94.

[34] Peter M, Wehmeier AS, Dittmann RW, et al. Effect of atomoxetine on quality of life and family burden: results from a randomized, placebo-controlled, double-blind study in children and adolescents with ADHD and comorbid oppositional defiant or conduct disorder. Qual Life Res 2011; 20: 691-702.

[35] Peter M, Wehmeier AS, Dittmann RW, et al. Effectiveness of Atomoxetine and Quality of Life in Children with AttentionDeficit/Hyperactivity Disorder as Perceived by Patients, Parents, and Physicians in an Open-Label Study. J Child Adolesc Psychopharmacol 2007; 17: 813-29.

[36] Perwien AR, Faries DE, Kratochvil CJ, et al. Improvement in health-related quality of life in children with ADHD: An analysis of placebo controlled studies of atomoxetine. J Dev Behav Pediatr 2004; $25: 264-71$

[37] Landgraf J, Abetz L, Wareb J. Child Health Questionnaire (CHQ): A users manual. Boston: Integrated Therapeutics Group.1996

[38] Mazzone L, Reale L, Mannino V, et al. Lower IQ is associated with decreased clinical response to atomoxetine in children and adolescents with attention-deficit hyperactivity disorder. CNS Drugs 2011; 25: 503-9.

[39] Sobel LJ, Bansal R, Maia TV. Basal ganglia surface morphology and the effects of stimulant medications in youth with attention deficit hyperactivity disorder. Am J Psychiatry 2010; 167: 977-86.

[40] Kaufman J, Bismaher B, Brent DA, et al. Schedule for Affective Disorders and Schizophrenia for School-Aged Children - Present and Lifetime Version (K-SADS-PL): initial reliability and validity data. J Am Acad Child Adolesc Psychiatry 1997; 36: 980-8.

[41] Swanson JM, Kraemer HC, Hinshaw SP, et al. Clinical relevance of the primary findings of the MTA: success rates based on severity of ADHD and ODD symptoms at the end of treatment. J Am Acad Child Adolesc Psychiatr 2001; 40: 168-79.

[42] Bussing R, Fernandez M, Harwood, et al. Parent and teacher SNAP-IV ratings of attention deficit hyperactivity disorder symp- 
toms: psychometric properties and normative ratings from a school district sample. Assessment 2008; 15: 317-28.

[43] Leiter RG. Instruction Manual for the Leiter International Performance Scale. Wood Dale, IL: Stoelting Co. 1979.

[44] Roid GM, Miller LJ. Leiter International Performance ScaleRevised: Examiners Manual. Wood Dale, IL: Stoelting Co. 1997.

[45] Bracken BA. Test di Valutazione dell'Autostima. Trento: Edizioni Erikson 1993.

[46] Yuang X. Correlation between self-esteem and mental health of secondary normal school students. Chin J Clin Psychol 2000; 8: 102-3.

[47] Shaw-Zirt B, Popali-Lehane L, Chaplin W, et al. Adjustment, social skills, and self-esteem in college students with symptoms of ADHD. J Atten Disord 2005; 8: 109-20.

[48] Bussing R, Zima BT, Perwien AR. Self-esteem in special education children with ADHD: relationship to disorder characteristics and medication use. J Am Acad Child Adolesc Psychiatry 2000; 30: $1260-9$.
[49] Barkley RA, Murphy KR, Kwasnik D. Motor vehicle driving competencies and risks in teens and young adults with attention deficit hyperactivity disorder. Pediatrics 1996; 98: 1089-95.

[50] Murphy KR, Barkley RA. Parents of children with attentiondeficit/hyperactivity disorder: psychological and attentional impairment. Am J Orthopsychiatry 1996; 66: 93-102.

[51] Wheeler J, Carlson CL. The social functioning of children with ADD with hyperactivity and ADD without hyperactivity: A comparison of their peer relations and social deficits. J Emot Behav Disord 1994; 2: 2-12.

[52] Hartup WW. Peer Relations. In: Hetherington EM, Ed. handbook of child psychology. Socialization, personality, and social development. New York: Wiley \& Sons. 1983.

[53] Whalen CK, Henker B, Dotemoto S. Teacher responses to the methylphenidate (Ritalin) versus placebo status of hyperactive boys in the classroom. Child Dev 1981; 52: 1005-14.

(C) Mazzone et al.; Licensee Bentham Open.

This is an open access article licensed under the terms of the Creative Commons Attribution Non-Commercial License (http://creativecommons.org/licenses/by-nc/3.0/) which permits unrestricted, non-commercial use, distribution and reproduction in any medium, provided the work is properly cited. 